systemic disease, the parenchyma sparing is advantageous from a prognostic view, especially because a function restriction of the lung in the progressive course is conceivable.

We described a patient and his surgical treatment, in which we used the lifesaving parenchyma-sparing operation. We believe that replacement of the pulmonary artery for aneurysms of the left pulmonary artery, as well as for aneurysms of the right pulmonary artery, in the intraparenchymal and intersegmental portion over the fissure of the lung is possible. This operation must be performed during extracorporal circulation because there is excessive back bleeding from the bronchial arteries. To our knowledge, we present the first successful interposition of the left pulmonary artery with implantation of the segmental arteries as a lung parenchyma-sparing procedure for pulmonary aneurysms.

We thank Ms Barbara Junghähnel from St.-Johannes-Hospital Dortmund for her drawings of the operation technique.

\section{References}

1. Butto F, Lucas RV Jr, Edwards JE. Pulmonary artery aneurysm. A pathologic study in five cases. Chest. 1987;91:237-41.
2. Tami LF, McElderry MV. Pulmonary artery aneurysm due to severe congenital pulmonary stenosis: case report literature review. Angiology. 1994;45:383-90.

3. Tuzun H, Hamuryudan V, Yildirim S, et al. Surgical therapy of pulmonary arterial aneurysm in Behçet disease. Ann Thorac Surg. 1996;61:733-5.

4. Fukai I, Masaoka A, Yamakawa Y, et al. Rupture of congenital peripheral pulmonary aneurysm. Ann Thorac Surg. 1995;59:52830 .

5. Slavin RE, de Groot WJ. Pathology of the lung in Behçet disease. Case report and review of the literature. Am J Surg Pathol. 1981; 5:779-88.

6. Barbero-Marcial M, Baucia JA, Jatene A. Valved conduits of bovine pericardium for right ventricle to pulmonary artery connections. Semin Thorac Cardiovasc Surg. 1995; 7:148-53.

7. Jacob JL, Garzon SA, Machado NC, et al. Pulmonary artery aneurysm. Report of two cases. Arq Bras Cardiol. 1989;53:33-7.

8. Arom KV, Richardson JD, Grover FL, et al. Pulmonary artery aneurysm. Am Surg. 1978;44:688-92.

9. Ungaro R, Saab S, Almond CH, et al. Solitary peripheral pulmonary artery aneurysms. Pathogenesis and surgical treatment. J Thorac Cardiovasc Surg. 1976;71:566-71.

10. Daily PO, Dembitsky WP, Daily RP. Dissectors for pulmonary thromboendarterectomy. Ann Thorac Surg. 1991;51:842-3.

\title{
Chondrosarcoma arising in the trachea: A case report and review of the literature
}

Mary Maish, MD, and Ara A. Vaporciyan, MD, Houston, Tex

$\mathrm{P}$

rimary malignant tracheal tumors are rare, accounting for only $0.2 \%$ of all malignancies of the respiratory tract. We present a case of tracheal chondrosarcoma in a 78-year-old man and review the literature.

\section{Clinical Summary}

A 78-year-old white man had a 3-month history of progressive shortness of breath with exertion. He did not have fever, cough, chills, night sweats, or hemoptysis. His primary care physician initially attributed his symptoms to worsening chronic obstructive pulmonary disease and treated him with inhalers and oral steroids. As his symptoms progressed, the patient became increasingly

\footnotetext{
From the Department of Thoracic and Cardiovascular Surgery, The University of Texas M. D. Anderson Cancer Center, Houston, Tex.

Received for publication May 12, 2003; accepted for publication May 28, 2003.

Address for reprints: Ara A. Vaporciyan, MD, 1515 Holcombe Boulevard, Box 445, Houston, TX 77030-4009 (E-mail: avaporci@notes.mdacc. tmc.edu).

J Thorac Cardiovasc Surg 2003;126:2077-80

Copyright $\odot 2003$ by The American Association for Thoracic Surgery

$0022-5223 / 2003 \$ 30.00+0$

doi:10.1016/S0022-5223(03)00949-8
}

bedridden, with dyspnea at rest, and he developed significant weight loss. He also began to experience episodic hoarseness. This symptom progression prompted further evaluation and he had a chest radiograph and then computed tomography (CT), which revealed a noncalcified mass in the lower third of the trachea with near compete obstruction of the lumen. An extratracheal extension of the mass was also present. The patient was transferred to our institution.

The patient was taken to the operating room where flexible and rigid bronchoscopy demonstrated a firm, white, nonfriable endotracheal mass emanating from the right side of the membranous trachea and obstructing $80 \%$ of the tracheal lumen. Endotracheal resection was performed via the rigid bronchoscope to provide an adequate airway. A postoperative CT scan confirmed the improved airway (Figure 1). Pathologic examination of the surgical specimen revealed a type I chondrosarcoma. The patient recovered uneventfully and was sent home for 3 weeks of intensive physical and nutritional therapy. He then underwent definitive resection.

The surgical approach utilized a right posterolateral thoracotomy, and the thorax was entered through the fourth intercostal space. A fourth intercostal muscle flap was harvested. The trachea was exposed anteriorly and posteriorly, and the mass was circumferentially dissected, with 5-mm margins proximally and distally. The tumor was well encapsulated, and both the right vagus and the left recurrent laryngeal nerve were identified and spared. A right 

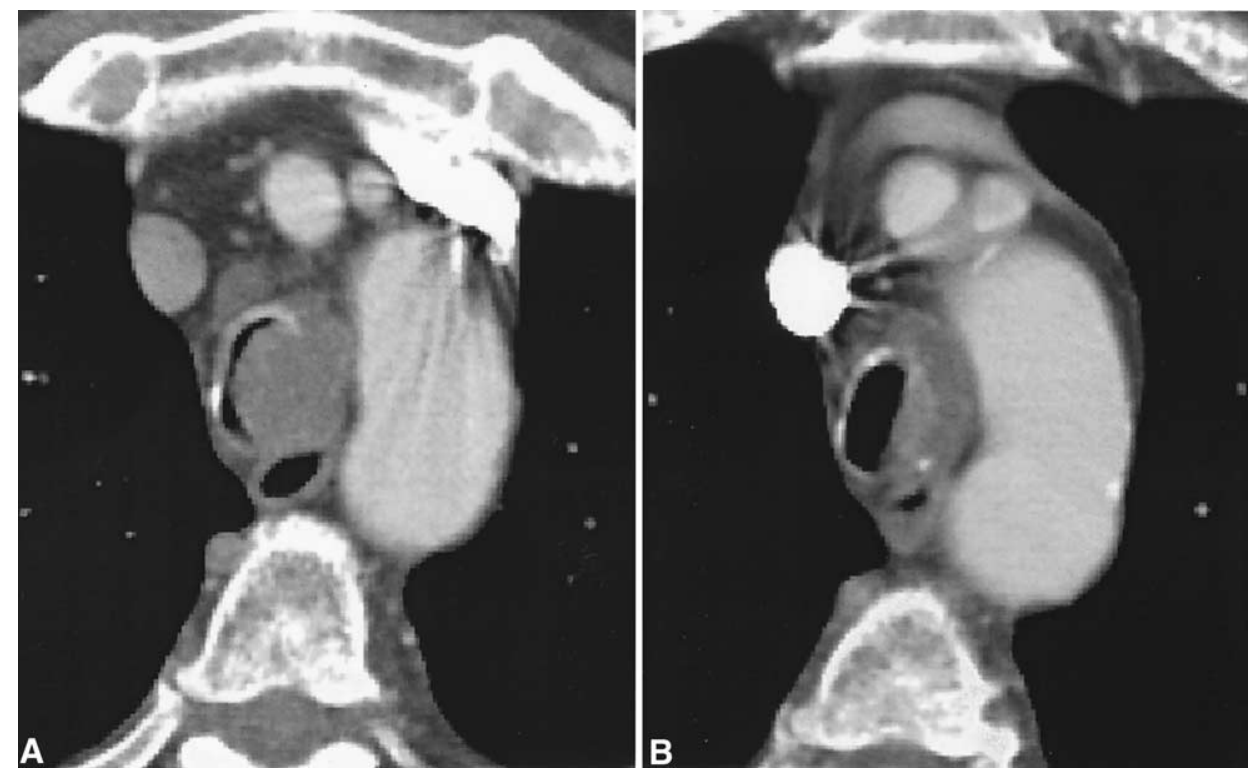

Figure 1. Computed tomography images demonstrating the tracheal lesion at presentation (A) and after endoscopic resection of the endoluminal disease (B).

TABLE 1. Characteristics of 15 reported cases with tracheal chondrosarcoma

\begin{tabular}{|c|c|c|c|c|c|c|c|c|}
\hline First author (year) & $\begin{array}{c}\text { Patient age, } \\
\text { years/sex }\end{array}$ & Symptoms & Calcification & $\begin{array}{l}\text { Duration of } \\
\text { symptoms to } \\
\text { Dx (months) }\end{array}$ & Treatment & $\begin{array}{c}\text { No. of } \\
\text { recurrences }\end{array}$ & \multicolumn{2}{|c|}{$\begin{array}{c}\text { Follow-up } \\
\text { (years) }\end{array}$} \\
\hline Jackson (1959) & $32 / \mathrm{M}$ & Cough & NR & 72 & Endoscopic resection & 0 & 6 & NED \\
\hline Daniels (1997) & 73/M & $\begin{array}{l}\text { Dyspnea, cough, } \\
\text { wheeze }\end{array}$ & NR & 7 & Endoscopic resection & 5 & 3 & AWD \\
\hline Farrell (1998) & $87 / M$ & Dyspnea & NR & 12 & $\begin{array}{l}\text { Refused resection } \\
\text { endoscopic resection } \\
\text { 2, radiotherapy }\end{array}$ & 2 & 1 & AWD \\
\hline Salminen (1990) & $57 / \mathrm{M}$ & Dyspnea, cough & Absent & 3 & Incomplete resection & 5 & 14 & DOD \\
\hline Matsuo (1988) & $72 / \mathrm{M}$ & $\begin{array}{l}\text { Dyspnea, } \\
\text { hemoptysis }\end{array}$ & Absent & 7 & $\begin{array}{l}\text { Incomplete resection, } \\
\text { laser resection, } \\
\text { resection }\end{array}$ & 1 & 0.5 & NED \\
\hline Moersch (1954) & NR & NR & NR & NR & Resection & NR & NR & NR \\
\hline Arevalo (1986) & 74/M & $\begin{array}{l}\text { Dyspnea, } \\
\text { pneumonia }\end{array}$ & Present & 0.25 & Resection & 0 & 1 & NED \\
\hline Fallahnejad (1973) & $48 / F$ & $\begin{array}{l}\text { Dyspnea, cough, } \\
\text { wheeze }\end{array}$ & Absent & 16 & Resection & 0 & 5 & NED \\
\hline Leach (1994) & $72 / \mathrm{M}$ & Dyspnea & Present & 36 & Resection & NR & NR & NR \\
\hline Kaneda (1993) & $64 / \mathrm{M}$ & Dyspnea & NR & NR & Resection & 0 & 1 & NED \\
\hline Slasky (1985) & $58 / \mathrm{M}$ & Dyspnea & Present & 24 & Resection & 0 & 2.5 & NED \\
\hline Weber (1978) & 71/M & $\begin{array}{l}\text { Dyspnea, cough, } \\
\text { hoarse }\end{array}$ & Present & 4 & Resection & 0 & 5 & NED \\
\hline Mine (1990) & $74 / \mathrm{M}$ & Dyspnea, cough & NR & NR & Laser debulking/resection & 0 & 2.8 & NED \\
\hline Kiriyama (1997) & $54 / \mathrm{M}$ & $\begin{array}{r}\text { Dyspnea, } \\
\text { wheeze }\end{array}$ & Present & 1 & Laser debulking/resection & 0 & 3.5 & NED \\
\hline Maish (2003) & 78/M & Dyspnea & Absent & 3 & Laser debulking/resection & 0 & 0.5 & NED \\
\hline
\end{tabular}

$D x$, Diagnosis; $M$, male; $N R$, not reported; $N E D$, no evidence of disease; $A W D$, alive with disease; $D O D$, dead of disease; $F$, female.

hilar release was performed, and the trachea was then divided at approximately 1 tracheal ring above and below the tumor. Frozen sections confirmed microscopically negative margins. The anasto- mosis was performed using interrupted 3-0 and 4-0 polydioxanone sutures for the cartilaginous and membranous portions of the trachea, respectively. Because the patient was elderly and had been 
treated with steroids, the fourth intercostal muscle flap was used to cover the anastomosis. Prior to extubation in the operating room, a bronchoscopy was performed, demonstrating a patent anastomosis. The patient had an unremarkable recovery and was discharged 7 days after surgery.

\section{Discussion}

Squamous cell and adenoid cystic carcinoma account for more than $80 \%$ of malignant tracheal tumors in adults. ${ }^{1}$ Squamous cell carcinomas seem to be more common in Europe, as indicated by a comparison of the study by Grillo and Mathisen ${ }^{2}$ with that of Gelder and Hetzel. ${ }^{3}$ The next most common tracheal malignancies, in order of decreasing incidence, are carcinoid tumor, adenocarcinoma, and small cell carcinoma. The remaining tracheal malignancies are very rare and include chondroma, chondrosarcoma, leiomyosarcoma, fibrosarcoma, chemodectoma, hemangiopericytoma, spindle cell sarcoma, synovial cell sarcoma, and melanoma of the trachea.

A review of the literature revealed only 14 reported cases of tracheal chondrosarcoma. ${ }^{1,4-15}$ Patient and clinical characteristics for those 14 patients and our patients are summarized in Table 1. The mean age of all 15 patients at presentation was 65 years (range 32-87 years). Fourteen of the 15 patients were men. The reported symptoms were dyspnea $(n=13 ; 93 \%)$, cough $(n=6 ; 43 \%)$, wheezing $(\mathrm{n}=3 ; 21 \%)$, hemoptysis $(\mathrm{n}=1 ; 7 \%)$, hoarseness $(\mathrm{n}=$ $1 ; 7 \%)$, and pneumonia $(\mathrm{n}=1 ; 7 \%)$ and were present for a mean of 15 months (range 1 week to 6 years) prior to diagnosis. The frequent combination of dyspnea, cough, and wheezing without hemoptysis often leads to a misdiagnosis of the condition as asthma or an exacerbation of chronic obstructive pulmonary disease, as had occurred with our patient.

The initial evaluation of the symptoms commonly involves chest radiography. Infrequently, an hourglass-shaped tracheal stripe may be noted, or if significant air has been trapped distal to the obstructing mass, the lung fields may be overinflated bilaterally. Frequently, however, chest radiographs are normal. CT provides the best visualization of the lesion, permitting accurate localization of the lesion and providing information about tumor length and extratracheal extension. Our review of the literature identified 5 cases, with various degrees of calcification, whereas 4 cases, including ours, had no evidence of calcification. The majority of cases also reported extratracheal extension of the mass. Magnetic resonance imaging has no added value compared with CT.

Bronchoscopy is the best method for the diagnosis and initial treatment of tracheal obstruction. When the airway is severely compromised, the patient should undergo a conscious evaluation in the operating room where the airway can be quickly controlled if necessary. Both flexible and rigid bronchoscopy should be utilized to evaluate the movement of the vocal cords, to identify the proximal and distal extent of the lesion, and to perform biopsies. Concomitant endoscopic resection and laser ablation can be performed to restore an adequate airway. Care must be taken not to dislodge a portion of the mass into a main stem bronchus. Once lodged distally, these masses can be difficult to retrieve and will embolize into the distal airway. Tattooing the airway with India ink at the most proximal and distal extents of the tumor can aid in defining the margins for surgical resection, especially if the tumor

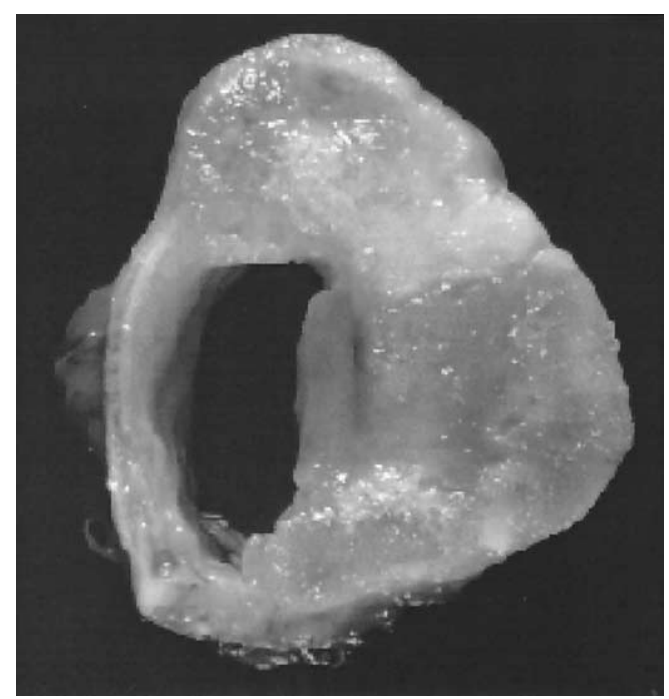

Figure 2. Cross section of resected specimen. The encapsulated nature of the tumor is readily apparent.

is initially removed by bronchoscopy and is primarily endoluminal.

Grossly, tracheal chondrosarcoma is well circumscribed and commonly covered with normal mucosa. It has been uniformly described as a firm or hard smooth mass and is commonly white or tan (Figure 2). Histopathologically, tracheal chondrosarcoma closely resembles the classic chondrosarcoma arising in bone rather than the mesenchymal chondrosarcoma variant that occurs in bone or soft tissue. ${ }^{16}$ The cytologic findings include round or polygonal cells with occasional binucleation, round hyperchromatic nuclei, and prominent nucleoli, all present in an amorphous pink-violet or light-blue background containing fragments of chondroid tissue. Distinguishing tracheal chondrosarcoma from benign chondroma can be difficult; however, low-grade chondrosarcomas and chondromas have similar natural histories and should be approached in similar manners. As with bony chondrosarcomas, the malignant transformation of a chondroma or a lowgrade chondrosarcoma to a high-grade (ie, "dedifferentiated") chondrosarcoma with hematogenous metastasis has been reported. $^{7}$

Complete surgical resection of the tumor, with primary reconstruction of the trachea, is the optimal treatment. Of the 15 patients reported in the literature (including the patient in our case), 5 underwent either incomplete surgical resection (positive surgical margins or a "debulking" procedure) or endoscopic resection only as the initial definitive treatment. The remaining 10 patients underwent complete surgical resection (removal of all gross disease with negative surgical margins) with or without initial laser debulking to restore a patent airway. Follow-up in our case and in 13 of the 14 reported cases, including all cases of complete resection, ranged from 3 months to 14 years (follow-up duration was not reported in the remaining case). Overall, there were 13 recurrences in 4 patients, all of whom had undergone incomplete resection or endoscopic resection. None of the patients who underwent complete surgical resection had a recurrence. 
Tumors arising in the lower third of the trachea are best approached through a right thoracotomy, whereas tumors in the middle and upper third can be reached with a collar incision. Every effort should be made to achieve negative microscopic margins while still allowing reconstruction with an end-to-end anastomosis. Although up to half of the trachea can be resected in younger patients, elderly patients have less tracheal mobility and must be approached more conservatively. Coverage of the tracheal anastomosis with a muscle flap or omentum is recommended, especially in deconditioned elderly patients and patients who have received steroids.

Chondrosarcoma, especially a lower-grade tumor, is not responsive to chemotherapy. Although chondrosarcoma has been considered radioresistant, there are reports of chondrosarcomas arising in bone being successfully treated with radiotherapy. ${ }^{16} \mathrm{In}$ addition, 1 report of the use of radiotherapy to treat laryngeal chondrosarcomas also exists. ${ }^{17}$ Therefore, although it is not considered to be a first-line treatment, radiotherapy may have a role in cases of surgically unresectable chondrosarcomas.

In conclusion, tracheal chondrosarcomas remain a rare but surgically treatable tracheal tumor. Their nondescript presenting symptoms often delay diagnosis. Aggressive complete surgical resection, with or without initial endoscopic airway restoration, is the treatment of choice; incomplete resections are complicated by high rates of local recurrence and the potential for malignant degeneration. For patients whose disease recurs or is deemed to be unresectable, radiotherapy may provide local control.

\section{References}

1. Weber AL, Shortsleeve M, Goodman M, Montgomery W, Grillo HC. Cartilaginous tumors of the larynx and trachea. Radiol Clin North Am. 1978;16:261-71.

2. Grillo HC, Mathisen DJ. Primary tracheal tumors: treatment and results. Ann Thorac Surg. 1990;49:69-77.
3. Gelder CM, Hetzel MR. Primary tracheal tumors: national survey. Thorax. 1993;48:688-92.

4. Jackson C, Jackson CL. Disease of the nose, throat and ear. Philadelphia: W. B. Saunders Company; 1959.

5. Daniels AC, Conner GH, Straus FH. Primary chondrosarcoma of the tracheobronchial tree, Report of a unique case and brief review. Arch Pathol. 1997;84:615-24.

6. Farrell ML, Gluckman JL, Biddinger P. Tracheal chondrosarcoma: a case report. Head Neck. 1998;20:568-72.

7. Salminen US, Halttunen P, Taskinen E, Mattila S. Recurrence and malignant transformation of endotracheal chondroma. Ann Thorac Surg. 1990;49:830-2.

8. Matsuo T, Kinoshita S, Iwasaki K, et al. Chondrosarcoma of the trachea. A case report and literature review. Acta Cytol. 1988;32:90812 .

9. Moersch HJ, Clagett OT, Ellis FH. Tumors of the trachea. $N$ Engl J Med. 1954;38:1096.

10. Arevalo M, Ordi J, Renedo G, Rami R, Oliva H. Chondrosarcoma of the trachea. Report of a case. Respiration. 1986;49:147-51.

11. Fallahnejad M, Harrell D, Tucker J, Forest J, Blakemore WS. Chondrosarcoma of the trachea. J Thorac Cardiovasc Surg. 1973;65:210-3.

12. Leach KR, Martinez FJ, Morelock JW, Korobkin MT, Orringer MB. Dyspnea and tracheal mass in an elderly man. Chest. 1994; 105:1555-6.

13. Kaneda Y, Nawata S, Sugi K, Hirayama T, Esato K. Chondrosarcoma of the trachea-report of a case. Nippon Kyobu Geka Gakkai Zasshi. 1993;41:1535-40.

14. Slasky BS, Hardesty RL, Wilson S. Tracheal chondrosarcoma with an overview of other tumors of the trachea. J Comput Tomogr. 1985;9: 225-32.

15. Kiriyama M, Masaoka A, Yamakawa Y, Niwa H, Fukai I, Yamada T. Chondrosarcoma originating from the trachea. Ann Thorac Surg. 1997; 63:1772-3.

16. Rosen G, Forchier CA, Mankin HJ, Selch MT. Bone tumors: neoplasms of the bone and soft tissue. In: Bast RC Jr, Kufe DW, Pollock RE, Weichselbaum RR, Holland JF, Frei E III, editors. Cancer medicine. 5th ed. Hamilton, Ontario, Canada: B. C. Decker Inc.; 2000. p. 1870-1902.

17. Gripp S, Pape H, Schmitt G. Chondrosarcoma of the larynx: the role of radiotherapy revisited-a case report and review of the literature. Cancer. 1998;82:108-15. 